\title{
PEMERINGKATAN RISIKO KEAMANAN SISTEM JARINGAN KOMPUTER POLITEKNIK KOTA MALANG MENGGUNAKAN CVSS DAN FMEA
}

\author{
Betta Wahyu Retna Mulya ${ }^{1}$, Avinanta Tarigan ${ }^{2}$ \\ 1'betta.wahyu@gmail.com, 2avinanta@gmail.com \\ ${ }^{12}$ Program Pascasarjana Teknik Informatika Universitas AMIKOM Yogyakarta
}

\begin{abstract}
Abstrak
Celah keamanan sistem jaringan komputer merupakan sebuah kelemahan, kekurangan atau lubang pada sistem, yang dapat dimanfaatkan oleh satu atau lebih dari penyerang untuk melakukan serangan yang dapat membahayakan kerahasiaan, integritas, atau ketersediaan suatu sistem.Proses penambalan memerlukan analisis celah keamanan sesuai dengan tingkat kerusakan untuk menentukan skala prioritas penanganan. Analisis yang digunakan dalam penentuan skala prioritas penanganan merupakan perpaduan metode analisis berbasis CVSS dan FMEA.Hasil analisis dari perpaduan dua metode menunjukkan bahwa nilai risk priority number dan jumlah vulnerability menjadi tolok ukur dalam memprioritaskan penanganan dan mitigasi risiko kepada pihak Politenik Kota Malang dengan urutan prioritas server singa, server sierra, server dino, dan server leopard. Skala prioritas menunjukkan bahwa tingkat kerentanan yang harus segera ditangani memiliki rentang nilai antara $40 \%$ sampai dengan $60 \%$. Penggabungan dua metode CVSS dan FMEA dapat menentukan peringkat penanganan berdasarkan dampak potensial yang ditimbulkan akibat kerentanan di sistem jaringan komputer Politeknik Kota Malang.
\end{abstract}

Kata kunci: sistem jaringan komputer, celah keamanan, CVSS, FMEA, mitigasi

\begin{abstract}
The vulnerability of a computer network system is a weakness, lack or hole in the system, which can be exploited by attackers to carry out an attack that may endanger the confidentiality, integrity or availability of a system. The filling process requires a security vulnerability analysis according to the severity to determine the priority scales of handling. The analysis used in determining priority scales of handling is the combination of CVSS and FMEA-based analysis method. The analysis result from both methods shows that the numbers of risk priority and vulnerability become a benchmark in risk prioritizing and mitigation the risk to Politeknik Kota Malang party, with the priority order: 'Singa', 'Sierra', 'Dino', and 'Leopard'. The priority scales show that the vulnerability levels, that must be handled, have number range between $40 \%$ up to $60 \%$. The combination of CVSS and FMEA methods can determine the handling level based on the potential impacts caused by the vulnerability in computer network system of Politeknik Kota Malang.
\end{abstract}

Keywords: network computer system, vulnerability, CVSS, FMEA, mitigation

\section{Pendahuluan}

Komunikasi data saat ini memiliki peranan penting diberbagai aspek aktivitas masyarakat. Kebutuhan akan komunikasi data dari tahun ke tahun meningkat. Peningkatan ini mencakup jumlah pengguna, jumlah akses data, dan lama waktu akses. Politeknik Kota Malang (POLTEKOM) membangun jaringan komputer berserta sistem informasinya untuk memenuhi kebutuhan komunikasi. Seiringnya waktu sistem informasi dan jaringan komputer POLTEKOM mengalami beberapa serangan baik dari dalam maupun dari luar. Perlunya analisis pemeringkatan risiko agar mengetahui cara penanganan yang tepat. Analisis yang dilakukan tentunya disesuaikan dengan kebutuhan keamanan dari sistem yang dibangun. Kebutuhan keamanan untuk sebuah sistem komputer berbeda-beda bergantung pada aplikasi-aplikasi yang didalamnya. Dilihat dari kebutuhan keamanan tersebut maka tidak ada jaminan apakah suatu sistem atau jaringan komputer dapat dikatakan secure atau reliable. Keamanan dapat ditingkatkan dalam skala berkelanjutan dari 0 hingga 1, atau dari kondisi tidak aman menjadi relatif aman [1].

Menghindari konten yang berbahaya bagi sistem dan jaringan komputer dibutuhkan tingkat kesadaran pengguna dalam akses sistem informasi dan jaringan komputer. Tingkat kesadaran pengguna seharusnya didasari oleh pengetahuan tentang celah keamanan dan jenis-jenis ancaman serta serangan dalam jaringan komputer. Guna meningkatkan tingkat kesadaran maka perlunya memahami tentang network security situation awareness. Network security situation awareness adalah teknologi keamanan baru yang didasarkan pada analisis data lampau dan deteksi status keamanan jaringan saat ini. Penilaian situasi keamanan jaringan memiliki hubungan erat antara perolehan elemen situasi dan prediksi kecenderungan kesadaran akan keamanan jaringan [2]. 
Penelitian ini akan dilihat bagaimana memastikan bahwa penggunakan Common Vulnerability Scoring System (CVSS) dan Failure Mode and Effect Analysis (FMEA) memungkinkan untuk menilai, membandingkan, memahami, serta memprioritaskan patching vulnerability pada sistem jaringan komputer, dengan demikian mampu memprioritaskan penanganannya sesuai dengan tingkat risikonya [3]. Analisis menggunakan CVSS digunakan untuk mengetahui dampak potensial akibat vulnerability sedangkan FMEA digunakan untuk mengetahui urutan prioritas penanganan potensi kegagalan yang ditimbulkan oleh celah keamanan.

\section{Metode}

\subsection{Sifat dan Pendekatan Penelitian}

Sifat jenis data dan analisis dari penelitian ini bersifat kualitatif, dengan melakukan pengkarakteristikan dari penemuan celah keamanan tersebut kemudian memberikan penilaian atau scoring menggunakan common vulnerability scoring system dan melakukan penentuan peringkat terhadap sistem yang paling terpengaruh. Menggunakan failure mode and failure analysis.. Pendekatan penelitian ini bersifat Mix-Method yaitu memadukan pendekatan kualitatif dan kuantitatif dalam metodologi pengambilan data pada penetration test. Pendekatan kualitatif didasari dari base metric group CVSS yaitu penilaian atas dasar kualitas sebuah kelemahan. Pendekatan kuantitatif didasari dari base scoring CVSS dan Risk Priority Number pada FMEA sebagai pengukur prioritas risiko terhadap penanganan kelemahan sistem.

\subsection{Alur Tahapan Penelitian}

Langkah-langkah penelitian yang dilakukan diantaranya :

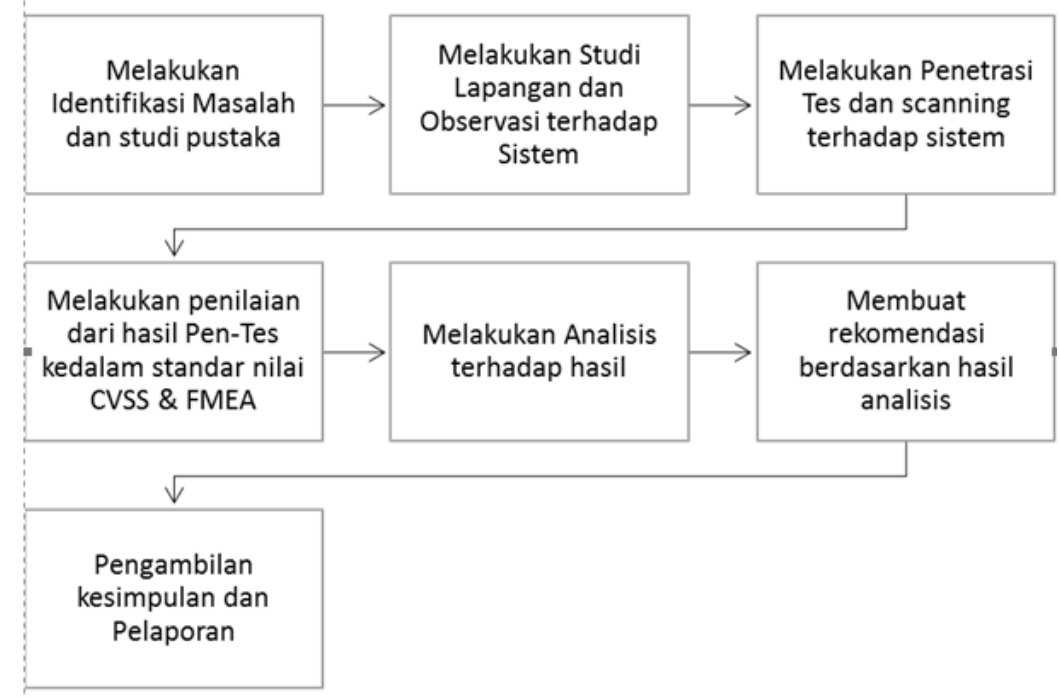

Gambar 1. Alur tahapan penelitian

Deskripsi alur tahapan penelitian

Tabel 1. Deskripsi alur tahapan penelitian

\begin{tabular}{|c|c|c|}
\hline No & Tahapan & Deskripsi \\
\hline 1 & Identifikasi masalah & $\begin{array}{l}\text { 1. Bagaimana penanganan celah keamanan sistem } \\
\text { jaringan komputer Politeknik Kota Malang? } \\
\text { 2. Bagaimana mengukur dampak potensial akibat } \\
\text { munculnya vulnerability pada sistem jaringan } \\
\text { komputer? } \\
\text { 3. Bagaimana menentukan skala prioritas } \\
\text { penanganan terhadap sistem jaringan komputer? }\end{array}$ \\
\hline 2 & Observasi sistem & $\begin{array}{l}\text { Melakukan pengamatan dan eksplorasi terhadap } \\
\text { perangkat keras dan perangkat lunak pada sistem } \\
\text { jaringan komputer Politeknik Kota Malang }\end{array}$ \\
\hline 3 & Tes penetrasi & Melakukan tes penetrasi mulai dari proses \\
\hline
\end{tabular}


$4 \quad$ Assessment hasil

$5 \quad$ Analisis hasil

6 Rekomendasi hasil

$7 \quad$ Pengambilan kesimpulan pemetaan, scanning, dan attacking menggunakan bantuan perangkat lunak zenmap, nessus, owasp, dan vega

Penilaian hasil tes penetrasi dikomparasi dengan hasil penilaian FMEA hasil observasi bersama pihak UPT PUSKOM Politeknik Kota Malang.

Menganalisa hasil komparasi dan mengabungkan kedua metode CVSS dan FMEA dan dibuat dalam diagram pareto

Memberikan rekomendasi kepada UPT PUSKOM untuk menangani kerentanan mulai dari manajemen perangkat keras hingga tingkat kesadaran pengguna Membuat kesimpulan dari hasil analisis.

\subsection{Topologi Jaringan Komputer}

Sistem jaringan komputer di Politeknik Kota Malang digunakan untuk memberikan layanan kepada mahasiswa, pegawai, maupun publik secara daring. Layanan ini meliputi website, internet, elearning, siakad, pmb, file sharing, jurnal, dan perpustakaan. Berikut daftar alamat domain dan subdomain pada Politeknik Kota Malang pada tabel 2 :

Tabel 2. Fungsi 4 Server

\begin{tabular}{llll}
\hline No & Hostname & Fungsi dan kegunaan & IP Private \\
\hline 1 & dino.poltekom.ac.id & Router dan network manajemen & 172.16 .0 .1 \\
2 & singa.poltekom.ac.id & Server cloud dan library & 172.16 .0 .3 \\
3 & leopard.poltekom.ac.id & Server Ims dan jurnal & 172.16 .0 .4 \\
4 & sierra.poltekom.ac.id & Server siakad dan PMB & 172.16 .0 .5 \\
\hline
\end{tabular}

Sistem jaringan komputer Politeknik Kota Malang terdiri dari 4 server, 2 switch unmanageable, 1 network storage, dan 1 router. Keempat server tersebut memiliki fungsi yang berbeda-beda seperti yang dijelaskan pada gambar 2 :

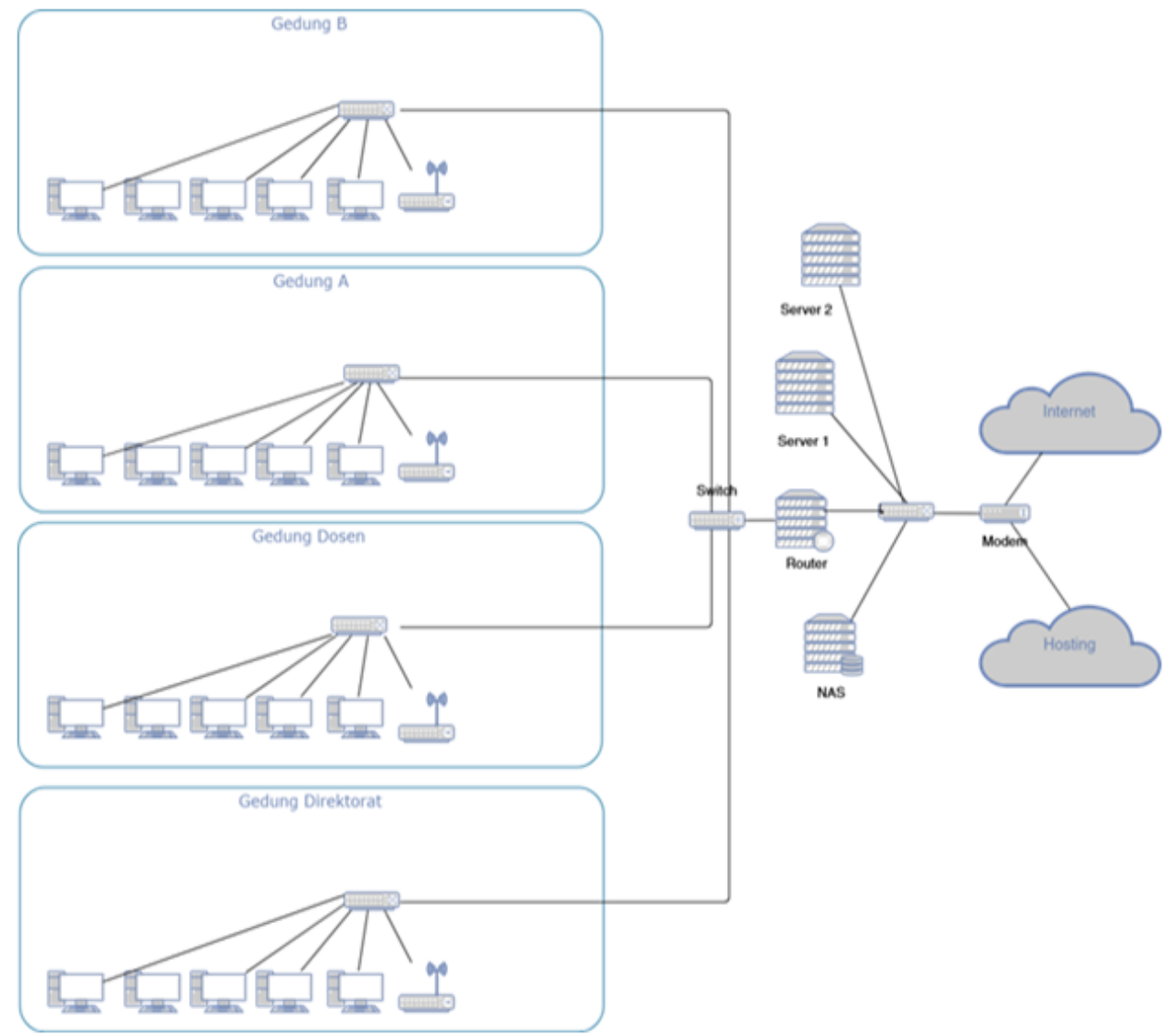

Gambar 2. Topologi Jaringan Politeknik Kota Malang 


\subsection{Metode Pengumpulan Data}

Pengumpulan data penelitian dilakukan dengan cara, sebagai berikut :

1. Studi dokumentasi, yaitu pengumpulan data penelitian dengan mempelajari buku, file, atau dokumen yang diperlukan seperti CVSS user guide, dan exploit database.

2. Wawancara, yaitu pengumpulan data penelitian dengan mewawancarai pihak penanggung jawab sistem terkait yaitu UPT PUSKOM tentang ancaman dan serangan pada sistem dan jaringan komputer di Politeknik Kota Malang.

3. Percobaan Laboratorium, yaitu pengumpulan data yang berupa percobaan yang dikendalikan terhadap target penelitian menggunakan penetration test tool. Perencanaan unit penelitian diukur berdasarkan base metric group CVSS versi 3 yang kemudian diperingkatkan berdasarkan FMEA sesuai dengan hasil dari RPN-nya

4. Observasi, yaitu pengumpulan data penelitian dengan pengamatan dari hasil penetration test terhadap sistem dan jaringan komputer di Politeknik Kota Malang terkait pengukuran celah keamanannya berdasarkan CVSS Versi 3 dan memberikan rating terhadap sistem mana yang memiliki risiko paling tinggi.

Pengumpulan data menurut perolehannya dan sifatnya sebagai berikut :

1. Data primer yaitu data yang dikumpulkan oleh peneliti melalui hasil dari tes penetrasi terhadap sistem jaringan komputer dengan mendapatkan hasil data kualitatif yaitu critical, high, medium, dan low.

2. Data Sekunder yaitu data yang dikumpulkan oleh peneliti secara tidak langsung dengan melibatkan tim UPT PUSKOM dalam melakukan penilaian pada FMEA Assessment yang menghasilkan data kuantitatif dengan rentang nilai mulai 0 sampai dengan 1000 .

\subsection{Metode Analisis Data}

Analisis data yang dilakukan dalam penelitian ini melalui pendekatan mix-method. Pendekatan ini digunakan untuk mengetahui kualitas sistem dan jaringan komputer Politeknik Kota Malang berikut metode analisis data :

1. Analisis terhadap pendekatan kualitatif base metric group melalui tes penetrasi terhadap sistem dengan menggunakan perangkat lunak vulnerability scanner NESSUS untuk mengetahui jumlah dan kualitas risiko di tiap sistemnya.

2. Analisis terhadap pendekatan kuantitatif base scoring melalui perhitungan dari hasil base metric group untuk mengetahui skala level ancaman beserta CVE Numbering. Proses penilaian score alurnya dapat dilihat pada gambar 3 .

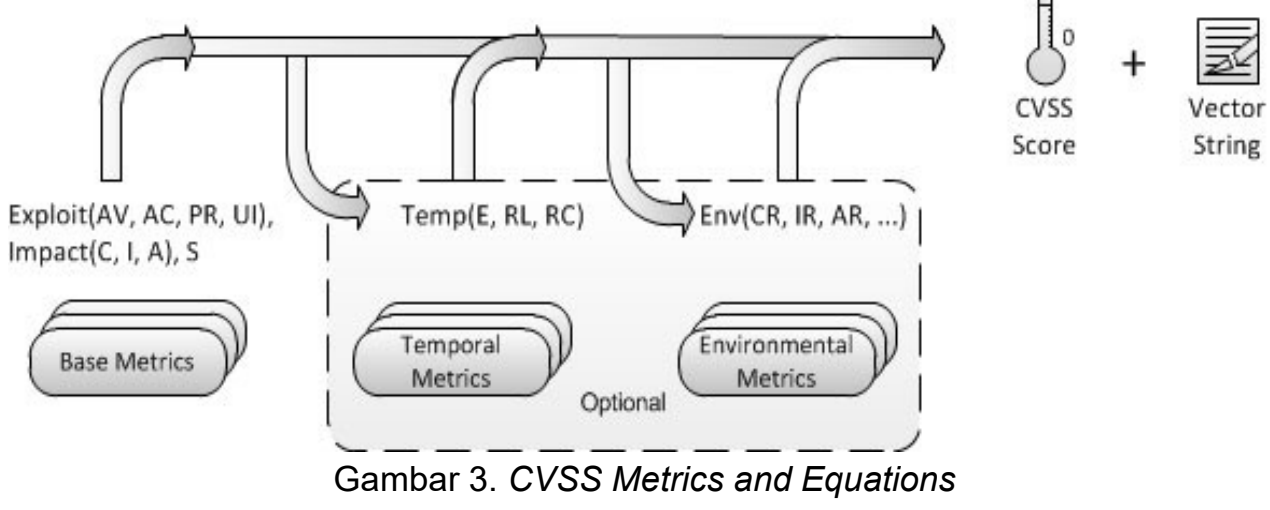

Rumus perhitungan base score

Definisi base score :

If (Impact sub score $<=0$ ) else, 0 )

Scope Unchanged Round up (Minimum[(Impact+Exploitability), 10])

Scope Changed Round up (Minimum[1.08 x (Impact + Exploitability),10])

Definisi impact sub score :

Scope Unchanged $6.42 \times$ ISCBase

Scope Changed $7.52 \times$ [ISCBase-0.029]-3.25 x [ISCBase-0.02] 
Perhitungannya Impact sub score :

ISCBase $=1-[(1-$ ImpactConf $) \times(1-$ ImpactInteg $) \times(1-$ ImpactAvail) $]$

Perhitungan Exploitability sub score :

$8.22 \mathrm{x}$ AttackVector $\mathrm{x}$ AttackComplexity $\mathrm{x}$ PriviligeRequired $\mathrm{x}$ UserInteraction

3. Analisis terhadap risiko menggunakan dengan menggunakan network vulnerability assessment checklist untuk mengetahui jumlah severity, occurence, dan detection.

4. Analisis terhadap risiko menggunakan form FMEA checklist yang dibuat berdasarkan diskusi peneliti dengan UPT PUSKOM untuk melakukan pemeringkatan risiko melalui perhitungan RPN.

\section{Hasil dan Pembahasan}

\subsection{Identifikasi Aset}

Penelitian ini dilakukan menggunakan aset sistem jaringan Politeknik Kota Malang. Hasil dari pengamatan aset secara langsung pada Politeknik Kota Malang didapatkan bahwa terdapat 4 buah server yang memiliki fungsi masing-masing.

Tabel 3. Daftar Aset Server Politeknik Kota Malang

\begin{tabular}{cccll}
\hline \multicolumn{1}{c}{ Aset } & IP Private & IP Public & \multicolumn{1}{c}{ Fungsi } & Sistem Operasi \\
\hline Dino & 172.16 .0 .1 & 36.66 .212 .105 & $\begin{array}{l}\text { Firewall, Router, dan } \\
\text { DNS Forwarder }\end{array}$ & Pfsense (freeBSD) \\
Singa & 172.16 .0 .3 & 36.66 .212 .106 & $\begin{array}{l}\text { Perpustakaan, OJS, } \\
\text { dan Weblog }\end{array}$ & Ubuntu Server 12.04 LTS \\
Leopard & 172.16 .0 .4 & 36.66 .212 .108 & LMS dan Cloud & CentOS 7.5 \\
Sierra & 172.16 .0 .5 & 36.66 .212 .109 & PMB dan Siakad & Ubuntu Server 16.04 LTS \\
\hline
\end{tabular}

\subsection{Analisis Vulnerability}

Vulnerabilities dan eksposur pada lingkungan sistem dan jaringan komputer dikarenakan terkait rendahnya pengelolaan sistem, patch yang tidak diinstal secara rutin, penggunaan kata sandi yang lemah, lemahnya pengaturan hak akses, dan sebagainya. Alasan utama dan tujuan di balik pengujian penetrasi harus mampu mengidentifikasi dan memperbaiki apa yang mendasari kegagalan dalam proses pengelolaan sistem sehingga mampu mendeteksi kerentanan pada saat pengujian. Kegagalan proses manajemen sistem yang paling umum ada di bidang berikut:

1. Konfigurasi sistem perangkat lunak

2. Konfigurasi aplikasi perangkat lunak

3. Perawatan perangkat lunak

4. Manajemen dan administrasi pengguna

Keempat bidang tersebut dikategorikan lagi berdasarkan rata- rata kerentanan yang sering mengakibatkan kegagalan sistem. Gambar 3 menunjukkan jumlah kerentanan berdasar kategori [4]. 


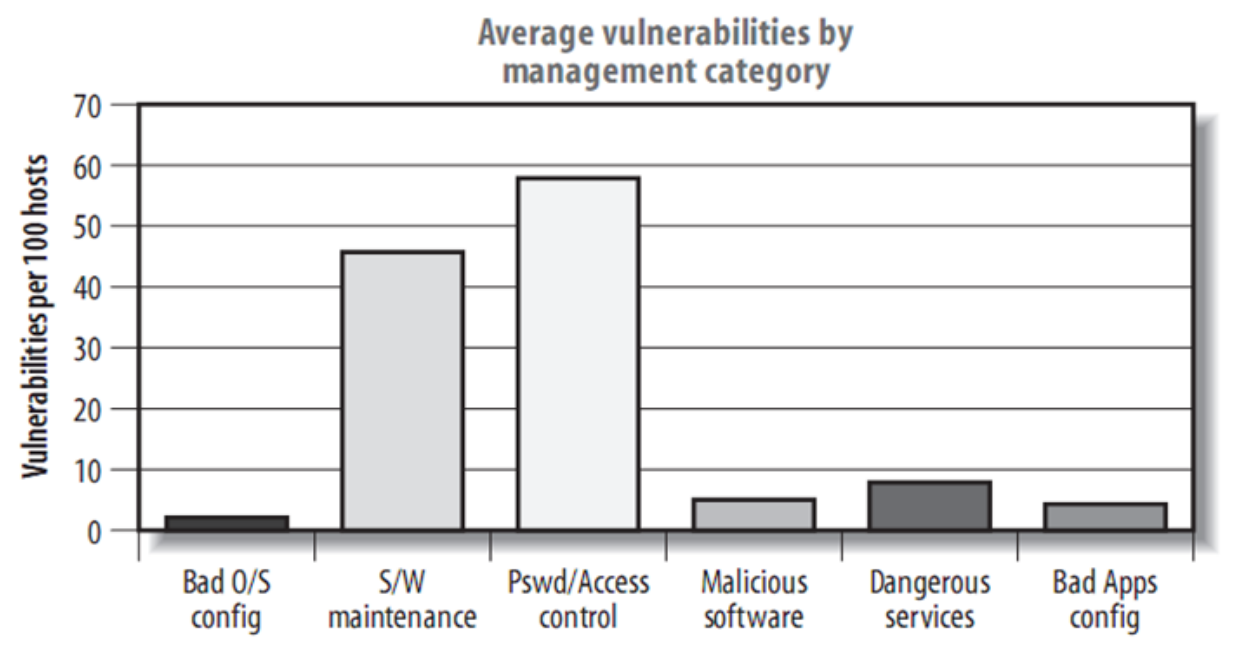

Gambar 4. Kerentanan berdasarkan kategori

\subsubsection{Analisis dengan CVSS}

Sistem jaringan komputer yang dimiliki oleh Politeknik Kota Malang semuanya terhubung kedalam internet. Untuk mengetahui celah keamanan pada sistem jaringan komputer dalam penelitian ini menggunakan tool analisis berupa vulnerability scanner yaitu NESSUS. Hasil dari proses ini didapatkan kategori vulnerabilitynya yaitu critical, high, medium, dan low yang dihasilkan berdasarkan base score selain itu terdapat juga solusi (remediation) untuk mengatasi vulnerability tersebut. Analisis menggunakan CVSS dalam prioritas penanganan kelemahan berdasarkan dari dampak bisnis menggunakan skala Franklin Covey.

Tabel 4. Skala Franklin Covey

\begin{tabular}{ccc}
\hline Skala & Tindakan & Keterangan \\
\hline $\mathbf{1}$ & Do Right Way & Segera dan Penting \\
$\mathbf{2}$ & Plan to Do & Tidak segera dan penting \\
$\mathbf{3}$ & Delegate & Segera dan tidak penting \\
$\mathbf{4}$ & Postpone/Dump & Tidak segera dan tidak penting \\
\hline
\end{tabular}

Penanganan keamanan pada 4 server tersebut berdasarkan tingkat kerusakan (severity) yang paling terdapat. Prioritas penanganan berdasarkan tingkat kerusakan hasil analisis vulnerability dengan CVSS ditunjukkan pada tabel 5 .

Tabel 5. Prioritas penanganan berdasarkan CVSS

\begin{tabular}{|c|c|c|c|c|c|}
\hline \multirow{2}{*}{ Host name } & \multicolumn{4}{|c|}{ Kategori Kelemahan } & \multirow{2}{*}{$\begin{array}{c}\text { Skala Prioritas } \\
\text { Penanganan }\end{array}$} \\
\hline & Extreme & High & Medium & Low & \\
\hline Singa & 32 & 149 & 141 & 15 & 1 \\
\hline Dino & 2 & 31 & 21 & 1 & 2 \\
\hline Sierra & 0 & 19 & 12 & 0 & 3 \\
\hline Leopard & 0 & 0 & 2 & 1 & 4 \\
\hline
\end{tabular}

Hasil proses scanning menggunakan Nessus menunjukkan jumlah vulnerability dan rekomendasi 


\section{TABLE OF CONTENTS}

Vulnerabilities by Host

- 172.16 .0 .1

Remediations

- Suggested Remediations

\section{Vulnerabilities by Host}

172.16.0.1

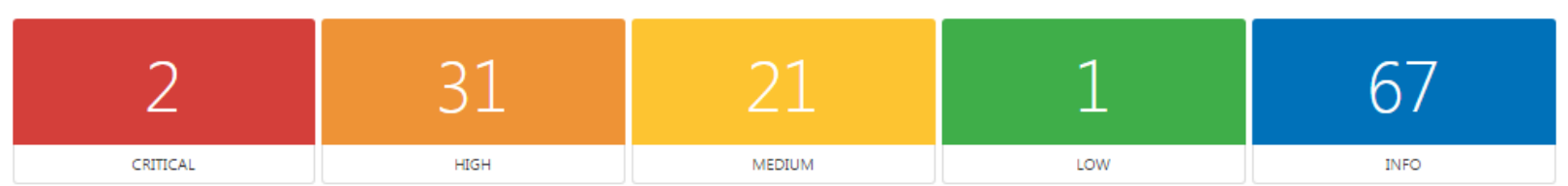

Scan Information

$\begin{array}{ll}\text { Start time: } & \text { Mon Jun } 25 \text { 17:20:38 } 2018 \\ \text { End time: } & \text { Mon Jun } 25 \text { 17:28:09 } 2018\end{array}$

End time: $\quad$ Mon Jun 25 17:28:09 2018

Host Information

DNS Name: dino.poltekom.ac.id

IP: $\quad 172.16 .0 .1$

MAC Address: $\quad$ 00:24:e8:42:63:8e 00:24:e8:42:63:8c 00:24:e8:42:63:88 00:24:e8:42:63:8a

OS: $\quad$ FreeBSD 10.3 - 5

Gambar 5. Salah satu hasil scanning menggunakan nessus

\subsubsection{Analisis dengan FMEA}

Berdasarkan hasil pengamatan pada waktu proses pengambilan data, mode kegagalan dan risiko yang dihasilkan pada sistem jaringan komputer Politeknik Kota Malang teridentifikasi. Selain pengamatan peneliti juga melakukan studi literatur-literatur tentang daftar potensi kegagalan yang dapat terjadi. Tabel 6 merupakan hasil analisis daftar potensi kegagalan yang terjadi pada sistem jaringan komputer Politeknik Kota Malang yang telah diidentifikasi oleh tim PUSKOM dengan peneliti.

Tabel 5. Daftar potensi kegagalan.

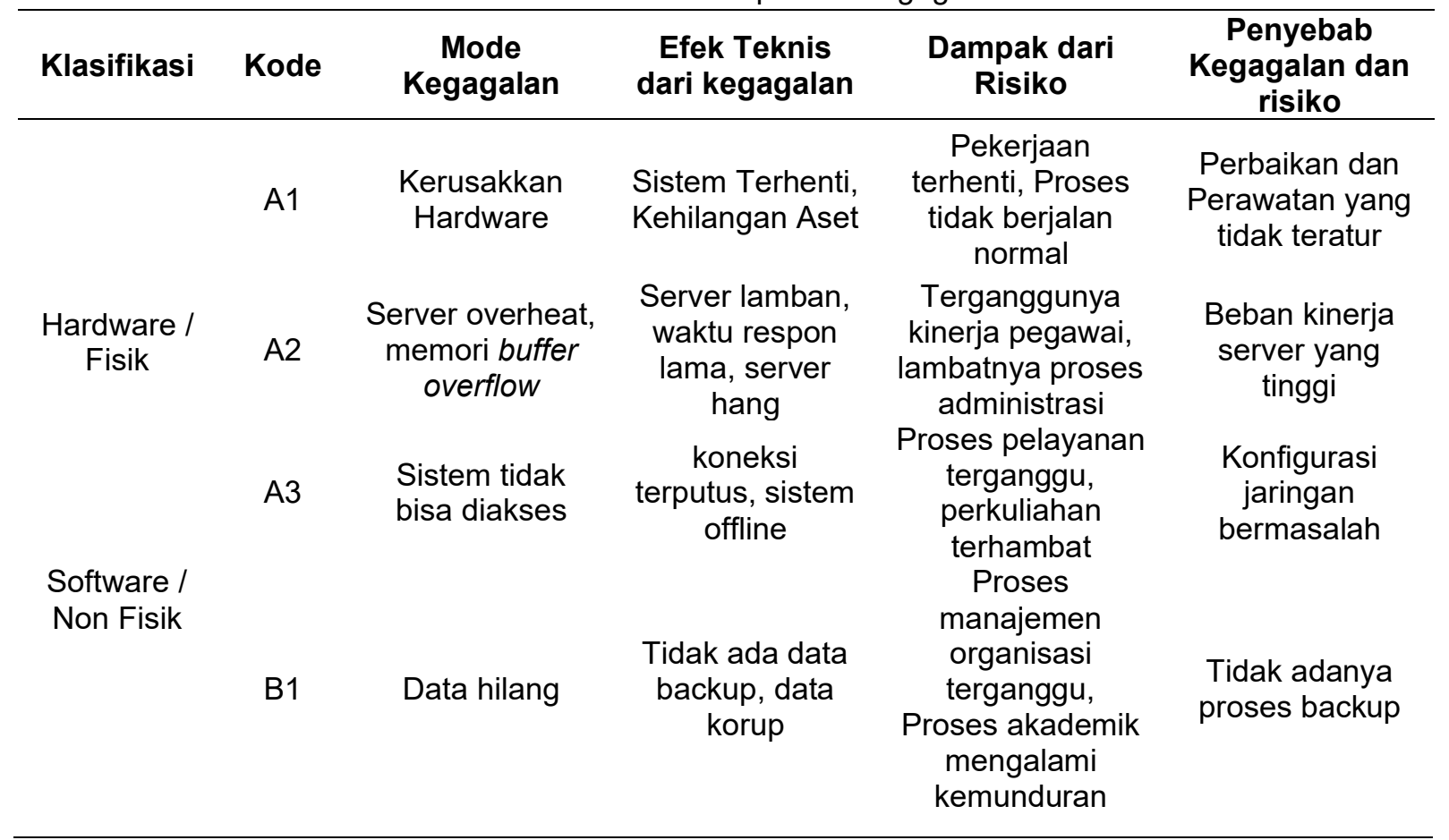




\begin{tabular}{|c|c|c|c|c|c|}
\hline & B2 & $\begin{array}{c}\text { Perangkat lunak } \\
\text { Memiliki } \\
\text { kelemahan }\end{array}$ & $\begin{array}{c}\text { Celah } \\
\text { masuknya } \\
\text { hacker, } \\
\text { penguasaan } \\
\text { sistem }\end{array}$ & $\begin{array}{l}\text { Modifikasi } \\
\text { perangkat lunak, } \\
\text { pencurian data, } \\
\text { kepercayaan } \\
\text { publik yang turun }\end{array}$ & $\begin{array}{c}\text { Perangkat lunak } \\
\text { using }\end{array}$ \\
\hline & B3 & $\begin{array}{l}\text { Penyerang } \\
\text { menanamkan } \\
\text { kode jahat }\end{array}$ & $\begin{array}{l}\text { Modifikasi } \\
\text { sistem, } \\
\text { terjadinya } \\
\text { hacking }\end{array}$ & $\begin{array}{l}\text { Kepercayaan } \\
\text { publik turun, } \\
\text { proses layanan } \\
\text { terganggu }\end{array}$ & $\begin{array}{l}\text { Konfigurasi } \\
\text { sistem yang } \\
\text { tidak benar }\end{array}$ \\
\hline & B4 & $\begin{array}{l}\text { Serangan } \\
\text { Hacker }\end{array}$ & $\begin{array}{l}\text { Sistem dikuasai, } \\
\text { Sistem crash, } \\
\text { pengalihan arus } \\
\text { informasi }\end{array}$ & $\begin{array}{l}\text { Pencurian data } \\
\text { perusahaan, } \\
\text { pemerasan }\end{array}$ & $\begin{array}{c}\text { Tidak adanya } \\
\text { filtering dan } \\
\text { pembatasan hak } \\
\text { akses }\end{array}$ \\
\hline & C1 & $\begin{array}{c}\text { Kehilangan } \\
\text { otorisasi }\end{array}$ & $\begin{array}{l}\text { Sistem } \\
\text { termodifikasi, } \\
\text { perubahan } \\
\text { konfigurasi }\end{array}$ & $\begin{array}{c}\text { Aplikasi error, } \\
\text { Kecepatan } \\
\text { jaringan menurun }\end{array}$ & $\begin{array}{c}\text { Penyalahgunaan } \\
\text { hak akses }\end{array}$ \\
\hline \multirow[t]{2}{*}{$\begin{array}{c}\text { User } \\
\text { Awareness } \\
\text { / Pengguna }\end{array}$} & $\mathrm{C} 2$ & Infeksi malware & $\begin{array}{l}\text { jaringan } \\
\text { terbebani, } \\
\text { penyadapan } \\
\text { informasi }\end{array}$ & $\begin{array}{c}\text { bocornya } \\
\text { informasi penting, } \\
\text { Kinerja pegawai } \\
\text { dalam melayani } \\
\text { transaksi } \\
\text { terganggu }\end{array}$ & $\begin{array}{l}\text { Pelanggaran } \\
\text { Aturan oleh } \\
\text { pegawai }\end{array}$ \\
\hline & C3 & $\begin{array}{l}\text { Sistem } \\
\text { mengalami } \\
\text { kerusakan }\end{array}$ & $\begin{array}{l}\text { Sistem tidak } \\
\text { berjalan } \\
\text { semestinya, } \\
\text { Terhambatnya } \\
\text { pekerjaan }\end{array}$ & $\begin{array}{l}\text { Pembengkakan } \\
\text { biaya, data } \\
\text { sensitif hilang } \\
\text { atau korup }\end{array}$ & $\begin{array}{l}\text { Karyawan yang } \\
\text { tidak kompeten }\end{array}$ \\
\hline
\end{tabular}

Pada tahapan ini dilakukan proses penentuan level severity, occurence, dan detection. Proses pada tahapan ini adalah mendeskripsikan serta mengidentifikasi sistem jaringan komputer berdasarkan potensi kegagalan dan risiko yang akan muncul. Penilaian pada tahapan ini adalah menilai level severity, occurence, dan detection menggunakan skala 1-10 yang nantinya akan menghasilkan nilai akhir berupa risk priority number (RPN) untuk mengetahui prioritas kegagalan yang segera ditangani. Hasil dari penilaian RPN ke 4 buah server sebagai berikut.

Tabel 6. Perhitungan RPN dari hasil analisis FMEA

\begin{tabular}{|c|c|c|c|c|c|c|c|c|c|c|c|c|}
\hline \multirow{2}{*}{ Nama Server } & \multirow{2}{*}{$\begin{array}{c}\text { Potensi } \\
\text { Kegagalan }\end{array}$} & \multicolumn{10}{|c|}{ Potensi Kegagalan } & \multirow{2}{*}{$\begin{array}{l}\text { Total } \\
\text { RPN }\end{array}$} \\
\hline & & A1 & A2 & A3 & B1 & B2 & B3 & B4 & C1 & $\mathrm{C2}$ & C3 & \\
\hline \multirow{4}{*}{ Server Dino } & Severity & 4 & 4 & 5 & 5 & 4 & 3 & 3 & 2 & 4 & 2 & \multirow{4}{*}{382} \\
\hline & Occurence & 5 & 2 & 5 & 3 & 3 & 2 & 4 & 2 & 4 & 2 & \\
\hline & Detection & 4 & 3 & 3 & 5 & 2 & 2 & 4 & 3 & 2 & 2 & \\
\hline & RPN & 80 & 24 & 75 & 75 & 24 & 12 & 48 & 12 & 32 & 8 & \\
\hline \multirow{4}{*}{ Server Singa } & Severity & 4 & 5 & 5 & 6 & 9 & 6 & 7 & 5 & 4 & 2 & \multirow{4}{*}{1079} \\
\hline & Occurence & 5 & 7 & 4 & 5 & 7 & 4 & 7 & 5 & 4 & 2 & \\
\hline & Detection & 4 & 2 & 3 & 5 & 3 & 4 & 6 & 4 & 2 & 2 & \\
\hline & RPN & 80 & 70 & 60 & 150 & 189 & 96 & 294 & 100 & 32 & 8 & \\
\hline \multirow{3}{*}{ Server Sierra } & Severity & 4 & 4 & 5 & 8 & 5 & 4 & 2 & 3 & 3 & 2 & \multirow{3}{*}{490} \\
\hline & Occurence & 5 & 3 & 7 & 5 & 3 & 3 & 4 & 4 & 3 & 3 & \\
\hline & Detection & 4 & 3 & 2 & 4 & 2 & 3 & 3 & 2 & 2 & 2 & \\
\hline
\end{tabular}




\begin{tabular}{llrrrrrrrrrrr}
\hline & RPN & 80 & 36 & 70 & 160 & 30 & 36 & 24 & 24 & 18 & 12 & \\
& & & & & & & & & & & & \\
& Severity & 4 & 4 & 5 & 7 & 2 & 3 & 2 & 2 & 3 & 2 & \\
Server Leopard & Occurence & 5 & 3 & 7 & 5 & 2 & 3 & 4 & 1 & 2 & 2 & 398 \\
& Detection & 4 & 3 & 2 & 4 & 2 & 2 & 3 & 1 & 2 & 2 & \\
& RPN & 80 & 36 & 70 & 140 & 8 & 18 & 24 & 2 & 12 & 8 & \\
\hline
\end{tabular}

\subsection{Pemeringkatan risiko keamanan}

Analisis vulnerability dan pemeringkatan risiko menunjukkan data kualitatif dan kuantitatif dari keempat server serta sistem jaringan komputer. Nilai RPN dari FMEA dan nilai vulnerability dari hasil perhitungan CVSS akan dijadikan tolok ukur dalam proses prioritas penanganan dan mitigasi risiko berupa rekomendasi kepada pihak UPT PUSKOM Politeknik Kota Malang. Penentuan skala prioritas penanganan guna menyelesaikan permasalahan yang ada maka penulis melakukan penggabungan skala dari hasil scanning vulnerability dan hasil RPN kemudian ditotal. Dari hasil tersebut akan dilakukan analisis menggunakan diagram pareto dengan prinsip yang menyatakan bahwa untuk banyak kejadian (dalam hal ini kelemahan), bahwa sekitar $80 \%$ dari efek tersebut disebabkan oleh $20 \%$ penyebabnya [5]. Tiap metode baik CVSS maupun FMEA masing-masing dapat menghasilkan urutan prioritas akan tetapi dari hasil perbandingannya kedua metode tersebut memiliki perbedaan dalam urutan prioritas. Berikut perbandingan antara kedua metode pada tabel 7 menunjukkan perbedaan dalam pemeringkatan risiko keamanan yang digunakan untuk penanganan atau penambalan celah keamanan.

\begin{tabular}{lcccc}
\multicolumn{5}{c}{ Tabel 7. Perbandingan Urutan Prioritas } \\
\multicolumn{1}{c}{ Hostname } & $\begin{array}{c}\text { Skor } \\
\text { CVSS }\end{array}$ & $\begin{array}{c}\text { Skor } \\
\text { FMEA }\end{array}$ & $\begin{array}{c}\text { Urutan Prioritas } \\
\text { CVSS }\end{array}$ & $\begin{array}{c}\text { Urutan Prioritas } \\
\text { FMEA }\end{array}$ \\
\hline Singa & 337 & 1416 & 1 & 1 \\
Dino & 55 & 445 & 2 & 3 \\
Sierra & 31 & 521 & 3 & 2 \\
Leopard & 3 & 401 & 4 & 4 \\
\hline
\end{tabular}

Hasil dari analisis didapatkan bahwa kedua metode tersebut masih memiliki perbedaan dalam hal prioritas penanganan. Perhitungan dari kedua metode tersebut dilakukan proses perhitungan ulang dengan membuat klasifikasi penilaian dan menghitung nilai rata-rata dari keempat klasifikasi.

1. Klasifikasi penilaian kegagalan hardware

2. Klasifikasi penilaian kegagalan software

3. Klasifikasi penilaian kegagalan userawareness

4. Klasifikasi penilaian vulnerability

Peneliti mengabungkan dua metode tersebut kemudian dibuat diagram pareto. Gambar 6 . menunjukan prioritas penanganan hasil pengabungan dua metode yang dapat dilihat pada tabel 8 .

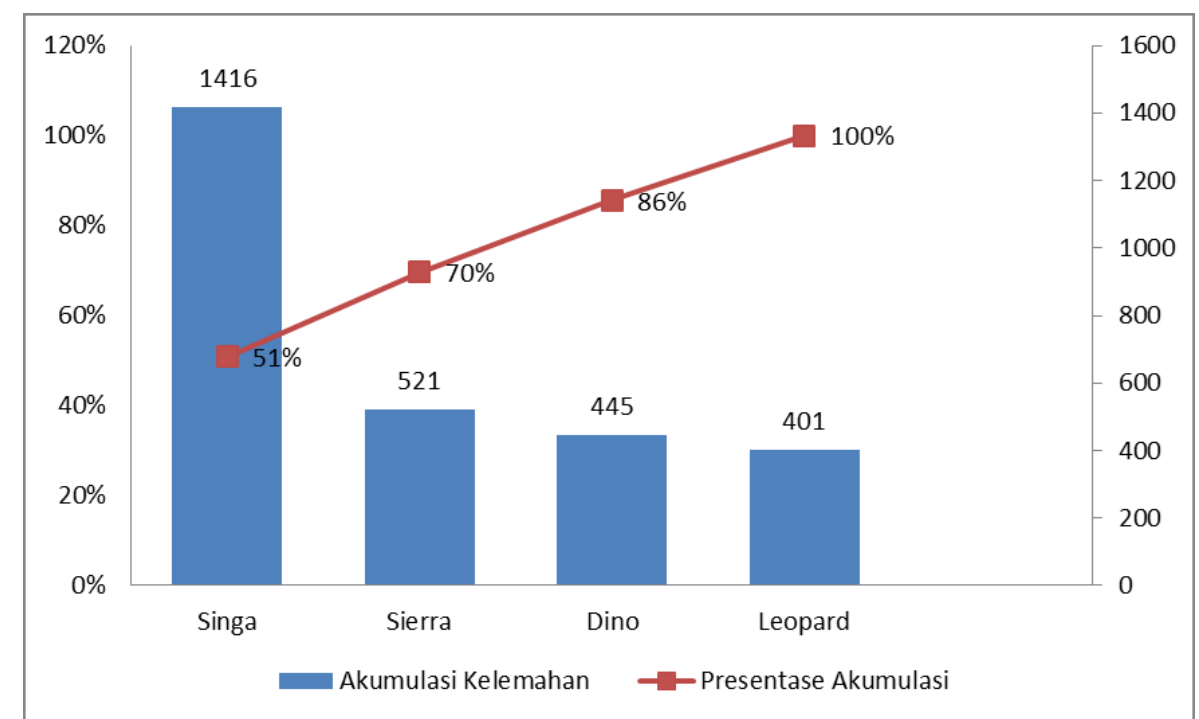

Gambar 6. Diagram Pareto 
Priotitas penanganan dilakukan sesuai dengan prosentase kegagalan yang digambarkan pada gambar 6. Peneliti memberikan keterangan server mana yang harus ditindak lanjuti penanganannya.

Tabel 8. Prioritas penanganan hasil penggabungan 2 metode

\begin{tabular}{cccccccc}
\hline Klasifikasi/host & A & B & C & SV & Total & Presentase & $\begin{array}{c}\text { Akumulasi } \\
\text { Presentase }\end{array}$ \\
\hline Singa & 210 & 729 & 140 & 337 & 1416 & $51 \%$ & $51 \%$ \\
Sierra & 186 & 250 & 54 & 31 & 521 & $19 \%$ & $70 \%$ \\
Dino & 179 & 159 & 52 & 55 & 445 & $16 \%$ & $86 \%$ \\
Leopard & 186 & 190 & 22 & 3 & 401 & $14 \%$ & $100 \%$ \\
\hline
\end{tabular}

\section{Kesimpulan dan Saran}

\subsection{Kesimpulan}

Berdasarkan hasil penelitian, berikut ini merupakan beberapa kesimpulan yang dapat diambil :

1. Hasil analisis dari penelitian ini menjabarkan bahwa sistem jaringan komputer Politeknik Kota Malang terdapat beberapa celah keamanan yang berstatus High Priority yaitu server singa.

2. Penggunaan Metode CVSS versi 3 hanya memperhatikan segi vulnerability saja tanpa memperhatikan celah keamanan dari faktor user awareness dan sistem infrastruktur jaringan komputer.

3. Penentuan variabel FMEA yaitu severity, occurence, dan detection belum memiliki standar baku. Penentuan variable tersebut berdasarkan potensi kegagalan yang dapat diamati oleh UPT PUSKOM.

4. Hasil analisis dari penggabungan dua metode CVSS dan FMEA dapat menentukan peringkat penanganan berdasarkan dampak potensial yang ditimbulkan akibat kerentanan dan celah keamanan disistem jaringan komputer Politeknik Kota Malang.

5. Hasil penelitian ini menunjukkan tingkat kerentanan sistem jaringan komputer memiliki nilai rentang $40 \% \mathrm{~s} / \mathrm{d} 60 \%$. Dengan demikian tujuan dari penelitian ini tercapai dengan menunjukkan tingkat kerentanan dan pemeringkatan risiko serta menjabarkan rekomendasi penanganan.

\subsection{Saran}

Pada penelitian ini peneliti memiliki keterbatasan dalam penerapan hasil rekomendasi, serta pembatasan dalam melakukan penetration test khususnya untuk situs web pada domain maupun subdomain poltekom.ac.id yang menyebabkan peneliti tidak dapat melakukan perhitungan ulang RPN dan menambahkan Common Weak Enumeration (CWE) dalam perhitungan analisis vulnerability. Berdasarkan kesimpulan yang telah diuraikan, maka untuk penelitian selanjutnya dapat melakukan perhitungan ulang RPN setelah menjalankan rekomendasi. Selain itu menambahkan fitur perhitungan CWE dalam proses penilaian website sistem informasi atau web profile. Peneliti juga dapat memakai SIX SIGMA sebagai peningkatan perbaikan kelemahan sistem jaringan komputer berdasarkan hasil RPN dari FMEA. Penerapan ISO/IEC 27001 atau SIX SIGMA tentang manajemen keamanan informasi belum dilaksanakan di Politeknik Kota Malang, kedepannya peneliti dan Tim PUSKOM melakukan penerapan ISO/IEC 27001 atau SIX SIGMA pada Politeknik Kota Malang.

\section{Ucapan Terima Kasih}

Peneliti mengucapkan terima kasih atas kesempatan dan izin yang telah diberikan oleh UPT PUSKOM Politeknik Kota Malang dalam menggunakan sistem jaringan komputer.

\section{Daftar Pustaka}

[1] F. Masykur, "ANALISIS VULNERABILITY WEB BASED APPLICATION MENGGUNAKAN NESSUS", Prosiding SENATEK, Fakultas Teknik, Universitas Muhammadiyah Purwokerto, p. 320-326, 2015.

[2] F. Li, Q. Huang, J. Zhu, and Z. Peng, "Network Security Risk Assessment Based on Item Response Theory," Proceedings of the 8th International Conference on Mobile Multimedia Communications, 2015.

[3] G. Spanos and L. Angelis, "Impact Metrics of Security Vulnerabilities: Analysis and Weighing," Information Security Journal: A Global Perspective, vol. 24, no. 1-3, pp. 57-71, Mar. $2015 .$.

[4] C. McNab, Network security assessment: know your network, 2nd ed. Sebastopol, CA: OReilly, 2017. 
[5] K. Ankunda, " The Application Of The Pareto Principle In Software Engineering", pp. 1-12, 2011.

[6] "Penetration Testing for IT Infrastructure," Core Security, 11-Dec-2017. [Online]. Available: https://www.coresecurity.com/content/penetration-testing. [Accessed: 27-Jan-2018]. 